\title{
PENGARUH JUMLAH LAPISAN BOTOL PLASTIK SEBAGAI ALAT SAMBUNG TERHADAP KUAT LENTUR KAYU SAMBUNGAN
}

\author{
Beni Wardiyanto ${ }^{1}$, Taufiq Lilo Adi Sucipto ${ }^{2}$, Anis Rahmawati ${ }^{2}$ \\ e-mail: beniwardiyanto@gmail.com
}

\begin{abstract}
ABSTRAK: Limbah kayu dan botol plastik banyak ditemukan di lingkungan. Limbah tersebut dapat digunakan kembali dengan menggabungkannya menjadi konstruksi sambungan kayu. Botol plastik digunakan sebagai alat sambung dengan cara dipanaskan pada suhu tertentu agar menyusut dan melekat pada kayu. Agar lekatan baik, dibutuhkan bentuk sisi kayu dengan desain tertentu yang berfungsi sebagai shear connector. Jumlah alat sambung dimungkinkan berpengaruh pada kekuatan sambungan. Penelitian ini membatasi pada kuat lentur untuk balok sederhana. Penelitian bertujuan untuk mengetahui apakah terdapat pengaruh yang signifikan pada kekuatan sambungan dengan 5 variasi jumlah lapisan botol plastik. Penelitian menggunakan metode kuantitatif ekperimen dan teknik analisa data menggunakan analisis Regresi. Pengambilan sampel dilakukan dengan sampling jenuh yaitu sebanyak 30 sampel,masing-masing variasi terdiri dari 6 sampel. Hasil penelitian menunjukkan bahwa, terdapat pengaruh antara jumlah lapisan botol plastik terhadap kuat lentur sambungan botol plastik pada balok sederhana. Kuat lentur sambungan balok sederhana tertinggi pada variasi 5 lapisan botol dengan rata-rata 140,92 $\mathrm{kgf} / \mathrm{cm}^{2}$, atau 16,63\% dari kekuatan lentur kayu tanpa sambungan.
\end{abstract}

Kata kunci : Kuat lentur, sambungan limbah botol plastik, balok sederhana.

\footnotetext{
${ }^{1}$ Mahasiswa Program Studi Pendidikan Teknik Bangunan FKIP Universitas Sebelas Maret

${ }^{2}$ Pengajar Program Studi Pendidikan Teknik Bangunan FKIP Universitas Sebelas Maret
} 


\title{
EFFECT OF PLASTIC BOTTLE LAYERS AS CONNECTIONS AGAINST FLEXURAL STRENGTH FOR TEACHING MATERIALS' SUPPLEMENT IN THE WOOD STRUCTURAL COURSE
}

\author{
Beni Wardiyanto ${ }^{1}$, Taufiq Lilo Adi Sucipto ${ }^{2}$, Anis Rahmawati ${ }^{2}$ \\ e-mail: beniwardiyanto@gmail.com
}

\begin{abstract}
Wood waste and plastic bottles are widely found in the environment. The waste can be reused by combining it into a wooden connection construction. Plastic bottles are used as a means of connection by heating at a certain temperature in order to shrink and attach to the wood. For the tighty stick, it takes a wooden side shape with a certain design that serves as a shear connector. The number of connecting devices is possible to affect the flexural of the connection. These study focused on flexural strength of to simple beams. The purpose of this study were to know whether there was significant influence on the flexural of the connection with 5 variations of the plastic bottles layers. This research was experimental method and data analys techniques used regression analysis. The sampling used saturated sampling with 30 samples, they were five samples in each variants. The result of the study were, there was relationship between the plastic bottles layers against the flexural strength of the plastic bottle connections on simple beam. Flexural strength of the connections on simple beams highest on 5 layers variation with the average 140,92 $\mathrm{kgf} / \mathrm{cm}^{2}$, or 16,63\% of the wood flexural strength without connection.
\end{abstract}

Keyword : Flexural strength, plastic bottle waste connections, simple beams.

\footnotetext{
${ }^{1}$ Student of Civil Engineering On Faculty of Teacher Training and Education Sebelas Maret University

${ }^{2}$ Lecture of Civil Engineering On Faculty of Teacher Training and Education Sebelas Maret University
} 
PENDAHULUAN

Kondisi limbah kayu dan botol plastik merupakan ancaman bagi keberlanjutan lingkungan dan akan mempengaruhi juga keberlanjutan sumber daya alam yang terbarukan maupun yang tidak. Menurut Ervianto (2012:83) untuk menjaga keberlanjutan sumber daya alam dengan memperpanjang daur hidupnya dapat dilakukan melalui upaya penggunaan kembali (reuse).

Fakri, Yohanes, dan Riyawan, (2015) mengemukakan bahwa pada pemanfaatan kayu menjadi suatu balok kayu hanya dapat dimanfaatkan sebanyak $57 \%$ atau menyisakan kayu terbuang sebanyak $43 \%$ berupa serbuk kayu, debu dan potongan kayu menjadi limbah.

Harian Jurnal Asia (2014) melaporkan bahwa rata-rata setiap orang menggunakan sekitar 168 botol plastik setiap tahunnya. Setiap hari 100 juta botol plastik digunakan di seluruh dunia, sekitar $86 \%$ botol plastik yang ada masih belum di-recycle dan ada sekitar 1500 botol berakhir di lautan setiap harinya. Indonesia berada di peringkat kedua dunia penghasil sampah plastik ke laut yang mencapai sebesar 187,2 juta ton (Jambeck dalam Wahyuni, 2016).

Perlu memanfaatkan limbah botol plastik dan menciptakan meterial konstruksi yang baru yaitu alat sambung kayu dengan botol plastik.

Micaela Pedros seorang desainer sebuah lembaga Sosial dan Kemanusiaan di kota London, menemukan cara untuk membuat kemasan sampah botol plastik menjadi sesuatu yang berarti, dan memperlihatkannya dalam sebuah proyek yang dinamakan "Joining Bottle”. Joining Bottle adalah teknik menggabungkan kayu menggunakan botol plastik yang disusutkan.
Kekuatan sambungan salah satunya dipengaruhi jumlah alat sambung (Sucahyo Sadiyo, dkk. 2012). Sehingga perlu adanya penelitian mengenai pengaruh kuantitas alat sambung botol plastik terhadap kekuatan sambungan kayu.

\section{METODE PENELITIAN}

Pengujian pada penelitian ini adalah uji lentur berdasarkan SNI 033939-1995. Sampel yang digunakan sebanyak 6 sampel pada setiap variasi untuk masing-masing pengujian dengan jenis kayu adalah kayu jati berukuran $5 \mathrm{x}$ $5 \times 76 \mathrm{~cm}$. Total sampel yang digunakan adalah 30 sampel.

Botol yang digunakan adalah botol plastik berkapasitas $1500 \mathrm{ml}$ dengan jenis, ukuran kemasan dan merek yang sama. Penelitian ini menggunakan botol berjenis Polyethylene Terephalate (PET) dengan panjang $15 \mathrm{~cm}$ dan terletak di tengah bentang kayu yang disambung. Pemilihan botol sebagai alat sambung di samakan dalam satu jenis botol plastik. Botol plastik yang digunakan dalam jenis, ukuran kemasan dan merek yang sama.

Teknik pengambilan sampel adalah dengan sampling jenuh dimana seluruh anggota populasi sebagai sampel dengan variabel bebas berupa variasi jumlah botol plastik yaitu lapisan botol plastik dari 1, 2, 3, 4 dan 5 lapisan di tunjukan pada gambar 1 . 


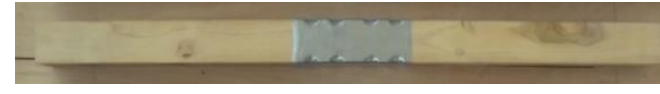

(1)

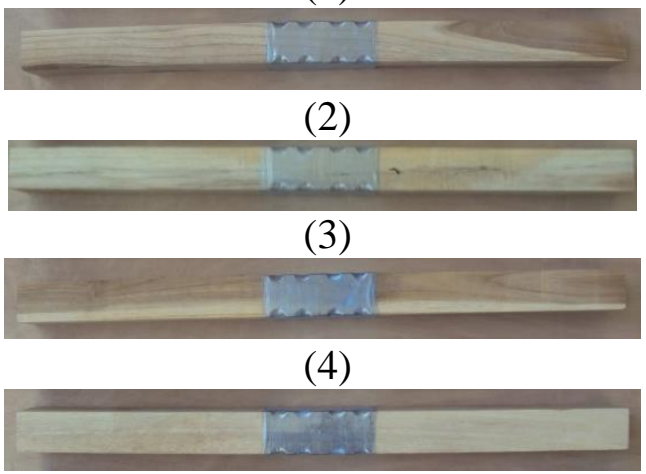

(5)

Gambar 1. Benda Uji (1) 1 lapisan, (2) 2 lapisan, (3) 3 lapisan, (4) 4 lapisan, dan (5) Lapisan

Uji kadar air ayu sampel dilakukan agar syarat pengujian terpenuhi. Kadar air maksimal untuk uji kuat lentur kayu adalah 20\%. Perhitungan kadar air menggunakan persamaan berikut:

$$
\mathrm{MC}=\frac{(A-B)}{B} \times 100 \%
$$

Dimana:

MC = kadar air kayu (\%)

$\mathrm{A}=$ berat sampel sebelum dioven $(\mathrm{g})$

$\mathrm{B}=$ berat sampel setelah dioven $(\mathrm{g})$

Apabila kadar air telah memenuhi, kayu berukuran 5 x $5 \mathrm{~cm}$ dipotong-potong dengan panjang $38 \mathrm{~cm}$ sebanyak 60 batang untuk disambung, dan 6 batang kayu utuh sepanjang $76 \mathrm{~cm}$.

Kayu tersebut kemudian diberi coakan pada setiap sudut penampang kayu sehingga ada 8 coakan untuk kedua batang kayu yang akan disambungkan sebagai penahan gaya geser (berfungsi sebagai shear connector) untuk memperkuat ikatan antara botol plastik dengan kayu. Bentuk coakan setengah lingkaran berdiameter $2 \mathrm{~cm}$ dengan desain seperti gambar 2 .

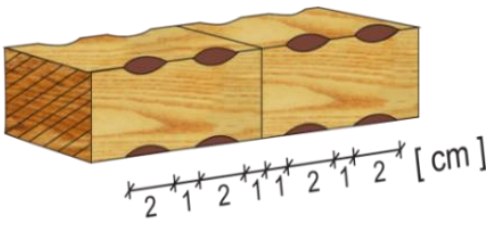

Gambar 2. Desain Coakan Sisi Kayu

Batang kayu ukuran panjang 38 $\mathrm{cm}$ digabungan menjadi satu batang seperti gambar 3 .

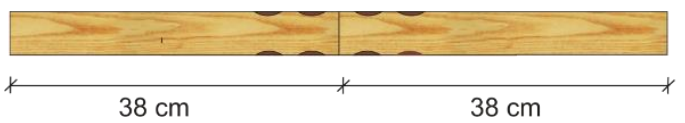

Gambar 3. Batang Kayu Balok

Sederhana

Penyambungan kayu dengan alat sambung botol plastik sepanjang $15 \mathrm{~cm}$ yang dilekatkan pada pertemuan ujung potongan kayu dengan cara dipanaskan menggunakan hot air gun. Desain benda uji dapat dilihat pada gambar 4 .

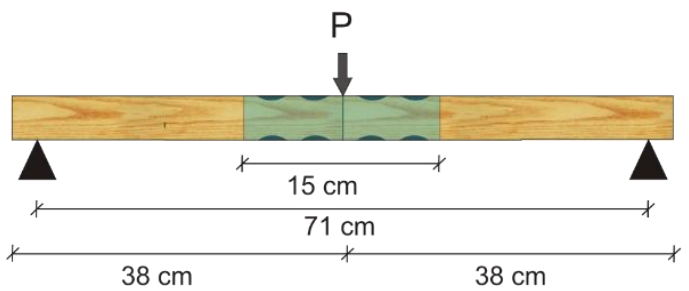

Gambar 4. Desain Benda Uji

Jarak hot air gun ke botol ketika proses pemanasan sekitar 7-10 cm. Botol plastik dipanaskan hingga melekat sepenuhnya pada kayu sebelum terjadi overheating. Overheating ditandai dengan adanya perubahan warna pada botol plastik yang menjadi putih dan bersifat getas. Apabila pada kondisi overheating ini tetap dilakukan proses pemanasan maka botol plastik dapat meleleh. Benda uji yang telah siap kemudian diuji kuat lentur dengan menggunakan mesin UTM (Universal Testing Machine).

Setelah pengujian, didapatkan data berupa maximum load atau beban maksimal yang diterima benda uji (P). 
Selanjutnya menghitung kuat lentur dengan persamaan berikut:

$$
\sigma \mathrm{lt}=\frac{3 \mathrm{PL}}{2 \mathrm{bh}^{2}}
$$

Dimana:

$$
\begin{array}{ll}
\text { olt } & =\text { kuat lentur }\left(\mathrm{kg} / \mathrm{cm}^{2}\right) \\
\mathrm{P} & =\text { beban uji maksimum }(\mathrm{kg}) \\
\mathrm{L} & =\text { jarak tumpuan }(\mathrm{cm}) \\
\mathrm{b} & =\text { lebar benda uji }(\mathrm{cm}) \\
\mathrm{h} & =\text { tinggi benda uji }(\mathrm{cm})
\end{array}
$$

Data yang didapatkan dari pengujian selanjutnya diolah dengan melakukan deteksi outlier yaitu membersihkan data dari data outlier. Data outlier pada penelitian ini adalah data yang memiliki z-score diluar range untuk data kurang dari 80 yaitu $-2,5$ hingga 2,5. Apabila ditemukan data outlier, maka data tersebut harus dibuang karena tidak dapat digunakan. Data ini kemudian dianalisis dengan menggunakan analisis Regresi melalui SPSS. Dilakukan juga uji normalitas dan linieritas sebagai uji prasyarat analisis regresi.

\section{HASIL PENELITIAN}

Pengujian kadar air berdasarkan SNI 03-6850-2002 menghasilkan ratarata kadar air $15,90 \%$. Kadar air tersebut telah memenuhi persyaratan pengujian lentur.

Hasil uji kuat lentur dapat dilihat pada Tabel 1. Kuat relatif merupakan perbandingan kuat lentur kayu tanpa sambungan dengan kayu sambungan dalam bentuk prosentase.
Tabel 1. Hasil Uji Kuat Lentur

\begin{tabular}{ccc}
\hline $\begin{array}{c}\text { Jumlah } \\
\text { Lapisan } \\
\text { Botol }\end{array}$ & $\begin{array}{c}\text { Kuat Lentur } \\
\left(\mathbf{k g f} / \mathbf{c m}^{\mathbf{2}}\right)\end{array}$ & $\begin{array}{c}\text { Kuat } \\
\text { Relatif }(\%)\end{array}$ \\
\hline 1 & 36,61 & 4,32 \\
2 & 61,01 & 7,21 \\
3 & 95,35 & 11,25 \\
4 & 117,48 & 13,86 \\
5 & 140,92 & 16,63 \\
Kayu utuh & 844,225 & 100 \\
\hline
\end{tabular}

\section{PEMBAHASAN}

Karakteristik sambungan ini saat pengujian plastik tidak mengalami robek, tetapi plastik mengalami deformasi secara perlahan-lahan. Plastik terlihat mudah tertarik dan bagian plastik yang masuk ke dalam coakan mudah kembali lurus saat dibebani lentur. Penelitian yang dilakukan oleh Turku et al, (2016) mengenai sifat mekanik struktur komposit kayu dengan beberapa jenis botol menunjukan kekuatan mekanik yang kecil dengan hilangnya susunan ikatan. Ikatan permukaan yang lemah mudah memisahkan antara kayu dengan plastik. Daya serap dari komposit ini bergantung pada ikatan permukaan yang lemah. Mudahnya lekatan antara plastik dan coakan terlepas karena lekatan kurang kuat. Perbedaan material penyusun komposit, maka antar matriks dan penguat harus saling berinteraksi antarmuka (interface), sehingga perlu ada penambahan material katalis berupa wetting agent (Pramono, 2008 dalam Turnip, 2010). Tida adanya wetting agent pada hubungan plastik dengan kayu menjadikan lekatan antara plastik dengan kayu menjadi mudah terlepas, terutama pada bagian tarik, seperti dapat dilihat pada gambar 5 . 


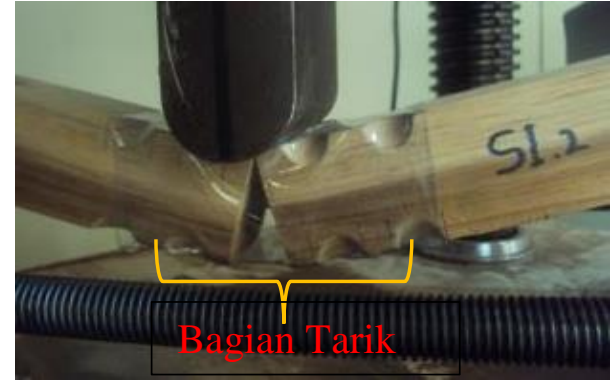

Gambar 5. Benda Uji Saat Pengujian

Nilai kuat lentur kayu sambungan ini juga dapat dipengaruhi oleh jumlah lapisan sambungan. Jumlah alat sambung sangat mempengaruhi kekuatan sambungan (Sadiyo dkk, 2012).

Lapisan sambungan yang hanya menggunakan satu lapis kurang memberikan kontribusi kekuatan lentur yang baik. Terbukti jika hanya satu lapis sambungan saja plastik akan lebih mudah tertarik dan bagian plastik yang masuk ke dalam coakan mudah kembali lurus karena ketebalan botol tipis. Senada dengan penelitian dari Diharjo (2011) yang menyatakan besarnya momen bending maksimum yang mampu ditahan meningkat secara konsisten seiring dengan penambahan jumlah laminat.

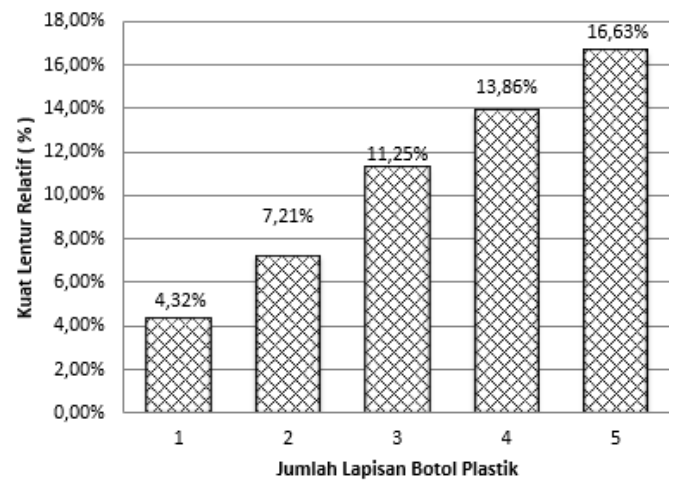

Gambar 6. Perbandingan Rasio Nilai Kuat Lentur Kayu Sambungan terhadap Kayu Tanpa Sambungan

Berdasarkan Gambar 6 sambungan botol plastik memiliki efektifitas sambungan 16,63\% terhadap bahan kayu atau kayu tanpa sambungan. Sehingga dapat disimpulkan bahwa inovasi sambungan botol plastik tidak cukup baik digunakan pada konstruksi kayu yang dominan menahan gaya lentur. Namun sambungan botol plastik ini memiliki keunggulan, diantaranya bersifat elastis, mudah dibuat dan dibentuk mengikuti bentuk dari kayu, dan bahan sambungan mudah dijumpai.

Sambungan botol plastik ini dapat langsung digunakan setelah botol plastik melekat erat. Kerusakan sambungan tidak sampai mengalami crack (patah) pada alat sambung (plastik), yang terjadi ditandai dengan adanya peristiwa pelelehan pada alat sambung (plastik) dibagian tarik (gambar 5).

\section{KESIMPULAN}

Terdapat pengaruh antara jumlah lapisan botol plastik terhadap kuat lentur sambungan botol plastik balok sederhana dengan alat sambung botol plastik. Variasi 5 jumlah lapisan botol plastik memberikan kuat lentur terbesar yaitu $140,92 \mathrm{kgf} / \mathrm{cm}^{2}$, atau $16,63 \%$ dari kekuatan kayu tanpa sambungan.

\section{SARAN}

Beberapa saran yang perlu disampaikan berdasarkan penelitian ini, diantaranya adalah perlu adanya penelitian lebih lanjut tentang berapa besar penyusutan botol plastik agar sambungan dapat terpasang sesuai perencanaan. Agar mendapat kuat lentur yang lebih baik, sambungan botol plastik perlu ditambahkah wetting agent seperti bahan katalis (lem, resin) untuk menambah lekatan plastik dengan kayu dan juga perlu meningkatkan variasi jumlah lapisan botol plastik diatas 5 lapisan untuk mendapatkan kuat lentur yang lebih optimal. 
DAFTAR PUSTAKA

Awaludin, A. (2005). Dasar-dasar Perencanaan Sambungan Kayu. Yogyakarta: Biro Penerbit Teknik Sipil UGM

Badan Standarisasi Nasional. (1995). SNI 03-3939-1995 Metode Pengujian Kuat Lentur Kayu di Laboratorium.

Badan Standarisasi Nasional. (2002). SNI 03-6850-2002: Metode Pengujian Pengukuran Kadar Air, Kayu dan Bahan Berkayu. Diperoleh pada 24 Januari 2017, dari https://www.scribd.com/ direct/228729652/

Diharjo, K. (2011). Kekuatan Bending Komposit Sandwich Serat Gelas dengan Core Divinycell-PVC H60 (Pengaruh Orientasi Serat, Jumlah Laminat dan Tebal Core terhadap Kekuatan Bending). Mekanika, 9 (2), 313-319.

Ervianto, Wulfram I. (2012). Selamatkan Bumi melalui Konstruksi Hijau. Yogyakarta: Andi Offset.

Fakri, Yohanes, dan Eko Riyawan. (2015). Kajian Potensi Limbah Kayu Industri Saw Mill Untuk Produk Panel Ringan Berongga Berbasis Teknologi Laminasi. Pekanbaru: Annual civil Engineering Seminar.

Harian Jurnal Asia. (2014, 15 November). Mengetahui Bahaya Sampah Plastik. Diperoleh pada 23 Januari 2017, dari http://www.jurnalasia.com/ ragam/mengetahui-bahayasampah-plastik/
Juniawan, E., Santosa, A.W., Jokosisworo, S. (2015). Analisa Kekuatan Sambungan Kayu Laban (Vitex Pinnata L.) pada Konstruksi Gading Kapal Tradisional. Jurnal Teknik Perkapalan, 3 (1), 73-82. Diperoleh pada 8 November 2017, dari https://ejournal3.undip.ac.id/ind ex.php/naval/article/view/7917

Sadiyo, S. dkk. (2012). Analisis Kekuatan Sambungan Geser Ganda Enam Jenis Kayu pada Berbagai Sesaran Menurut Diameter dan Jumlah Baut. Jurnal Perennial, 8 (2), 52-61. Diperoleh pada 18 September 2017, dari http://journal.unhas.ac.id/index. $\mathrm{php} /$ perennial/article/view/215

Safitri, E. \& Gunawan, P. (2010). Pengujian Sambungan Finger Joint untuk Mengkaji Kuat Lentur pada Balok Kayu. Media Teknik Sipil, X (2), 113-118. Diperoleh pada 18 Desember 2017, dari http://media.sipil.ft.uns.ac.id/ind ex.php/mts/article/view/108

Sucipto, T.L.A. dkk. (2015). Kajian Penerapan Green Building Pada Gedung Bank Indonesia Surakarta. JIPTEK: Jurnal Ilmiah Pendidikan Teknik dan Kejuruan, VII (2), 17-24. Diperoleh pada 18 Januari 2017, dari

https://jurnal.uns.ac.id/jptk/articl e/view/12692

Turku, I. et al. (2016). Characterization of wood plastic composites manufactured from recycled plastic blends. Composite Structures, 161 (2017), 469-476. 
Diperoleh pada 18 September 2017, dari https://ac.elscdn.com/S0263822316320025/1 -s2.0-S0263822316320025main.pdf

Turnip, R. (2010). Penggunaan Komposit Epoksi Berpengaruh Serat Kevlar Sebagai Bahan Alternatif Mengatasi Kebocoran Pipa. Universitas Indonesia.

Wahyuni, T. (2015, 14 Maret). Jenis Sampah dan Lama Proses Penghancurannya. CNN Indonesia. Diperoleh pada tanggal 12 Februari 2017, dari https://www.cnnindonesia.com/ gaya-hidup/20150314083106255-39061/jenis-sampah-danlama-proses-penghancurannya

Wahyuni, T. (2016, 23 Februari). Indonesia Penyumbang Sampah Plastik Terbesar Ke-dua Dunia. CNN Indonesia. Diperoleh pada tanggal 12 Februari 2017, dari https://www.cnnindonesia.com/ gaya-hidup/ indonesiapenyumbang-sampah-plastikterbesar-ke-dua-dunia 